\title{
Nerve fibre degeneration in the brain in amyotrophic lateral sclerosis
}

\author{
Martin R Turner
}
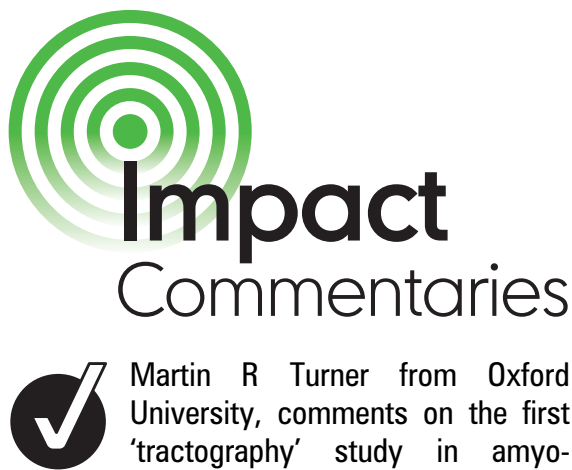
Martin $\mathrm{R}$ Turner from Oxford University, comments on the first 'tractography' study in amyoEDITOR'S trophic lateral sclerosis, and CHOICE a landmark in the construct of a multi-system cerebral neurodegeneration

An advertisement in The New Scientist dated 9 May 1957 read: "Technician or junior technician required for histology in neuropathological work. Some knowledge of photography an advantage. Salary according to experience. Apply in writing stating age and experience to Dr Marion Smith, National Hospital for Nervous Diseases, Queen Square, London WC1". Three years later the Glasgow trained neuropathologist (1910-1998) and President of the British Neuropathological Society published a paper entitled 'Nerve fibre degeneration in the brain in amyotrophic lateral sclerosis', based on detailed postmortem examination of seven cases.

Cerebral involvement in amyotrophic lateral sclerosis (ALS) was already recognised. Seventy years prior, Gowers noted in his Manual of diseases of the nervous system: "With this degeneration of the cells and peripheral fibres there is usually also associated a degeneration of the pyramidal tracts in the cord, sometimes, at least, to be traced up to the motor cortex of the brain." Acknowledging important contributions by Holmes and Davison, Smith's

Correspondence to Dr M R Turner, Oxford University Nuffield Department of Clinical Neuroscience, John Radcliffe Hospital, West Wing Level 3, John Radcliffe Hospital, 0xford OX3 9DU, UK; martin.turner@clneuro. ox.ac.uk

\author{
NERVE FIBRE DEGENERATION IN THE \\ BRAIN IN AMYOTROPHIC LATERAL \\ SCLEROSIS ${ }^{1}$ \\ Author: Smith MC \\ Year published: 1960 \\ Number of times cited: 95
}

specific aim was to study the degeneration of myelinated fibre tracts, although she simultaneously confirmed wider extramotor (including frontal) cortical involvement.

Smith's study can be regarded as an early form of 'tractography', a white matter pathway study that can now be performed in vivo using MRI. Indeed, her published drawings of prominent and consistent corpus callosum as well as corticospinal tract involvement in ALS are strikingly similar to images obtained non-invasively 50 years later using diffusion tensor imaging. ${ }^{2}$ Her observations on the organisation of internal capsule fibres according to their cortical projections is also reproducible using MRI based tractography. ${ }^{3}$ Smith acknowledged a key limitation of this type of analysis, persistent to this day, namely that: "...we cannot say categorically that the degeneration starts here and goes there, as we can about the degeneration resulting from circumscribed lesions".

Smith's cohort included a long survivor (12 years) in whom there is reported: "...little active degeneration in the cord or lower brain-stem, although there is in the cerebral hemispheres". It is now recognised that upper motor neuron predominant ALS, as well as the much rarer exclusively upper motor neuron phenotype termed primary lateral sclerosis, may also have significantly slower progression. Her observation of degenerating fibre tracts projecting to the thalami is in keeping with the in vivo demonstration of particularly prominent microglial activation here. ${ }^{4}$ She also noted involvement of the basal ganglia, notably including the substantia nigra, in three of the seven brains, in keeping with the recognised clinical overlap of parkinsonism. ${ }^{5}$

Smith co-authored other important anatomical papers with the Queen Square neurologist Peter Nathan (1914-2002), including a study of the course of the corticospinal tracts and an examination of the anatomical substrate for the Babinski reflex. Prescient of the era of TDP43-defined ALS, she commented at the end of this paper that: "It is possible that essential information relevant to the functional anatomy of the human central nervous system may be derived from the detailed study of routine neuropathological material, apart from the possibility of making observations contributing to an understanding of the aetiology of the disease."

First published in the Journal of Neurology Neurosurgery and Psychiatry 1960;23:269-82.

Competing interests None.

Provenance and peer review Commissioned; not externally peer reviewed.

Received 17 July 2011

Accepted 19 July 2011

J Neurol Neurosurg Psychiatry 2012;83:382.

doi:10.1136/jnnp-2011-300984

\section{REFERENCES}

1. Smith MC. Nerve fibre degeneration in the brain in amyotrophic lateral sclerosis. J Neurol Neurosurg Psychiatry 1960;23:269-82.

2. Filippini N, Douaud G, Mackay CE, et al. Corpus callosum involvement is a consistent feature of amyotrophic lateral sclerosis. Neurology 2010;75:1645-52.

3. Zarei M, Johansen-Berg $\mathrm{H}$, Jenkinson $\mathrm{M}$, et al. Twodimensional population map of cortical connections in the human internal capsule. J Magn Reson Imaging 2007;25:48-54.

4. Turner MR, Cagnin A, Turkheimer FE, et al. Evidence of widespread cerebral microglial activation in amyotrophic lateral sclerosis: an [(11)C](R)-PK11195 positron emission tomography study. NeurobiolDis 2004:15:601-9.

5. Hudson AJ. Amyotrophic lateral sclerosis and its association with dementia, parkinsonism and other neurological disorders: a review. Brain 1981:104:217-47. 